$$
\begin{gathered}
\text { 일 도시의 초등학교 학생의 수면습관과 행동, 정서, } \\
\text { 주의력, 학습과의 관계 }
\end{gathered}
$$

탁희종 ${ }^{1)} \cdot$ 이지호 ${ }^{2)} \cdot$ 이장명 ${ }^{3)}$. 정석훈 ${ }^{4)} \cdot$ 이재원 ${ }^{5)} \cdot$ 심창선 $^{2)} \cdot$ 윤재국 $^{2)} \cdot$ 성주현 $^{2)} \cdot$ 방수영 $^{1)}$

울산대학교 의과대학 울산대학교병원 정신과학교실, ${ }^{1}$ 울산대학교 의과대학 울산대학교병원 산업의학과학교실, ${ }^{2}$

울산대학교 공과대학, ${ }^{3)}$ 울산대학교 의과대학 서울아산병원 정신과학교실, ${ }^{4)}$ 국립환경과학원 실내환경과 ${ }^{5}$

\title{
Differences in Sleep Patterns are Related to Behavior, Emotional Problems, Attention and Academic Performance in Elementary School Students of a South Korean Metropolitan City
}

\author{
Hee-Jong Tak, M.D. ${ }^{1}$, Ji-Ho Lee, M.D., Ph.D. ${ }^{2)}$, Chang-Myung Lee, Ph.D. ${ }^{3)}$, \\ Seok-Hoon Chung, M.D., Ph.D ${ }^{4)}$, Jae-Won Lee ${ }^{5)}$, Chang-Sun Sim, M.D., Ph.D. ${ }^{2)}$, \\ Jae-Goog Yoon, M.D. ${ }^{2)}$, Joo-Hyeon Sung, M.D. ${ }^{2}$ and Soo-Young Bhang, M.D., M.P.H. ${ }^{1)}$ \\ ${ }^{1)}$ Department of Psychiatry, Ulsan University Hospital, College of Medicine University of Ulsan, Ulsan, Korea \\ ${ }^{2)}$ Department of Occupational \& Environmental Medicine, Ulsan University Hospital, College of Medicine, \\ University of Ulsan, Ulsan, Korea \\ ${ }^{3}$ College of Engineering, University of Ulsan, Ulsan, Korea \\ ${ }^{4}$ Department of Psychiatry, College of Medicine, University of Ulsan Asan Medical Center, Seoul, Korea \\ ${ }^{5)}$ National Institute of Environmental Research, Incheon, Korea
}

Objectives : The aim of this study was to investigate the sleep patterns of South Korean elementary school children and whether the differences in sleep patterns were related to behavior, emotional problems, attention and academic performance.

Method : This study included a community sample of 268 boys and girls from fourth-, fifth- and sixth-grade classes in a South Korean metropolitan city from November to December 2010. The primary caregivers completed a questionnaire that included information on demographic characteristics, as well as the Child's Sleep Habit Questionnaire (CSHQ), the Korean version of Child Behavior Checklist (K-CBCL), the Korean version of the Learning Disability Evaluation Scale (K-LDES), the Korean version of ADHD Rating Scale (K-ARS) and the Disruptive Behavior Disorder Scale (DBDS). We conducted analyses on the CSHQ individual items, between the subscales, on the total scores and on the K-CBCL, the K-LEDS, the K-ARS and the DBDS.

Results : Based on the findings from the CHSQ, the subjects had significantly higher scores for bedtime resistance $(9.18 \pm$ $2.17)$, delayed sleep onset $(1.32 \pm 0.62)$, the sleep duration (4.19 \pm 1.52$)$ and daytime sleepiness $(14.10 \pm 3.55)$ than the scores from the previous reports on children from western countries. The total CHSQ score showed positive correlations to all subscales of the K-CBCL : withdrawn ( $r=0.24, p<.005)$, somatic complaint $(r=0.24, p<.005)$ and anxious/depressive $(r=0.38, p<.005)$. Bedtime resistance was associated with oppositional defiant disorder $(r=0.15, p<.05)$ and a positive correlation was demonstrated between sleep anxiety and the oppositional defiant disorder score $(r=0.13, p<.05)$, night waking and the conduct disorder score $(r=0.16, p<.05)$. Delayed sleep onset was related with low performance on the K-LDES with respect to thinking $(r=-0.17$, $\mathrm{p}<.05)$ and mathematical calculation $(\mathrm{r}=-0.17, \mathrm{p}<.05)$.

Conclusion : The results of this study reconfirm Korean children's problematic sleep patterns. Taken together the results provide

접수완료 :2011년 6월 1일 / 심사완료:2011년 7월 28일

Address for correspondence:Soo-Young Bhang, M.D., M.P.H., Department of Psychiatry, Ulsan University Hospital, College of Medicine, University of Ulsan 290-3 Jeonha-dong, Dong-gu, Ulsan 682-714, Korea

Tel : +82.52-250-7070, Fax : +82.52-232-3309, E-mail : dresme@dreawmiz.com

이 연구는 국립환경과학원의 환경기술개발사업 연구비 지원을 받은 것임. 
that the reduced sleep duration and disruption of sleep pattern can have a significant impact on emotion, behavior, performance of learning in children. Further studies concerning more diverse psychosocial factors affecting sleep pattern will be helpful to understanding of the sleep health in Korean children.

KEY WORDS : Elementary School Student $\cdot$ Sleep $\cdot$ Behavior $\cdot$ Emotional Problem $\cdot$ Attention $\cdot$ Academic Performance.

\section{서 론}

수면은 각성상태에서 뇌와 신체조직에 발생한 손상을 회복 시키고 에너지를 보존하고 전신 및 특히 뇌조직에 휴식을 제공 하여 일상생활의 기능을 조직하고 유지할 수 있게 해준다. 수 면 단계 중 렘수면은 학습 및 기억 과정에도 중요한 역할을 하 고, 뇌의 성장과 발달에 중추적인 역할을 담당한다.)

수십 년간 서구에서는 수면박탈과 수면장애가 일상생활의 기능과 삶의 질에 미치는 영향에 대해서 연구해 왔다. 수면 장 애와 행동, 정서, 주의력, 학습문제의 연관성에 대한 다양한 연 구들이 있다. 학령기 소아들의 수면장애의 치료가 학업성취도 의 개선에도 도움을 줄 수 있다는 ${ }^{2}$ 일부 연구자들의 보고와 수면박탈과 수면장애가 인지기능과 낮 동안의 각성상태에 부 정적 영향을 미친다는 연구가 있었다. ${ }^{3)}$ 수면은 행동학적 측면 에도 영향을 끼치는데 수면이 부족한 아동은 사고 발생률이 더 높고, ${ }^{4}$ 실험적으로 소아에게 수면을 제한할 경우 학습문제, 집중력의 문제가 증가되는 것으로 밝혀졌다.5) 양적으로나 질적 으로 정상적인 수면이 박탈되면 사고나 실수의 가능성이 높아 지고 주의집중력 및 감정조절능력, 판단력이 떨어지며 학습에 도 부정적인 영향을 미치게 되고, ${ }^{6}$ 성인에 비하여 수면의 영향 에 더 취약한 소아청소년에서 수면 문제가 발생할 경우 행동조 절의 어려움을 야기할 수 있다.

우리나라 소아들의 경우 외국에 비하여 늦게 자고 수면시간 이 상대적으로 적다는 보고들이 있다. ${ }^{89}$ 사교육에 과도하게 노 출되어 있는 상황에서 학습을 위하여 수면시간을 제한하는 학 부모로 인해 아동의 수면시간이 줄어들 가능성이 높고 결과적 으로, 아동의 정서행동인지의 건강한 발달에 부정적인 영향을 미칠 수 있다. ${ }^{10)}$

현재까지, 우리나라에서는 소아들의 구체적인 수면습관 및 심리학습정서에 미치는 영향에 대한 연구들이 부족한 실정이 다. 서완석 등1ㅣㅇㅣ 보고한 바 따르면 학습성취도가 상대적으로 높은 아이들의 총수면량이 길다는 보고가 있으나 행동 및 정서 와 수면과의 연관성에 대한 논문은 전무한 실정이다. 따라서 이 연구에서는 지역사회 소아의 수면습관을 조사하고, 소아의 수면 문제가 정서행동학습에 어떠한 부정적인 영향을 미치는 지 단면 연구를 통하여 검증하고자 한다.

\section{방 법}

일 광역시의 세 초등학교를 선정하여 $4,5,6$ 학년 각각 한 반씩을 무작위로 선정하였다. 2010년 11월 6일부터 12월 8일까 지 269명의 아동을 대상으로 학부모설문조사를 시행하였다. 먼저 선정된 3 개의 학교를 대상으로 학교 당국과 담당 교사 에게 검사의 목적 및 방법을 설명하고 연구참여에 대한 동의 를 얻었다. 다음으로 각반 담임 교사를 통해 연구참여에 대 한 취지 설명 및 동의 여부를 확인하였다. 연구참여에 동의하 기로 서명한 대상자에 한해 각 학생의 부모에게 소아수면습 관설문지 및 행동, 학습, 주의력에 대한 설문을 배부하였다. 본 연구는 울산대학교병원 임상연구심의위원회(IRB)의 승인 을 받았다.

\section{평 가}

\section{1) 소아수면습관 설문지(Child's Sleep Habit Questionnaire, CSHQ)}

2004년 Judith A. Owens에 의하여 개발된 척도로, 입면저 항(bedtime resistance), 입면지연(sleep onset delay), 수면량 (sleep duration), 수면불안(sleep anxiety), 입면후각성(night wakings), 사건수면(parasomnia), 수면호흡장애(sleep disordered breathing), 주간졸림증상(daytime sleepiness)을 측정 한다. 5 개의 역산 문항을 포함하여 총 33 개 항목으로 이루어 져 있으며, 일주일에 5일 이상 관찰되면 '자주 그런다', 일주일 에 2 4일 관찰되면 ‘때때로 그런다', 일주일에 하루 미만으로 관찰되면 '드물다'에 표시하게 되어 있는 1 3점의 리커르트 척 도이다. 결과는 총점 및 8개 소척도로 보고된다. 6개 문항-(item) 의 입면저항, 1 개 문항의 입면지연, 3 개 문항의 수면량, 4 개 문 항의 수면불안, 3 개 문항의 입면후각성, 7 개 문항의 사건수면, 3 개 문항의 수면호흡장애, 8 개 문항의 주간졸림증상으로 구성 된다. 이전 연구에서 이 척도의 내적 신뢰도는 지역사회 아동 에 있어서는 0.68 , 수면장애 클리닉 환자에서는 0.78 로 보고된 바 있다. ${ }^{12)}$ 우리나라 아동을 대상으로 $\mathrm{CSHQ}$ 를 사용한 연구로 는 주의력결핍 과잉행동장애(attention-deficit hyperactivity disorder, $\mathrm{ADHD}$ ) 아동군과 정상군의 수면의 주관적 객관 적면을 비교한 연구 ${ }^{13)}$ 와, $\mathrm{ADHD}$ 아동의 약물치료 전후의 수 
면의 질을 평가한 연구가 있다. ${ }^{14}$ 현재까지 이 척도의 한국어판 표준화연구는 없으며, 본 연구에서 신뢰도를 평가하기 위해 Cronbach의 알파 및 소척도간 상관을 계산하였다

\section{2) 한국어판 부모용 아동행동평가척도(Korean version of Child Behavior Checklist, K-CBCL)}

CBCL는 Achenbach 등 $(1983,1991)$ 에 의해 개발된 아동 행동평가 도구로서 아동 행동의 여러 측면들에 대해 부모가 관찰한 바를 측정하는 것으로, 사회능력척도(social competence scale)와 행동문제척도(syndrome and total problem scale)로 나누어져 있다. 한국판 개발은 1990년에 오경자 등 15$)$ 이 수행하였으며 만족할만한 신뢰도 및 타당도를 보였고, 이 후 많은 임상연구에서 사용되고 있다. 행동문제척도는 모두 118 개 문항으로 이루어져있으며, 총 12 개의 소척도로 구성되 어있는데, 위축(withdrawan), 신체증상(somatic complaint), 불안/우울(anxious/depressed), 사고의 문제(thought problems), 사회적 미성숙(social problems), 주의집중 문제(attention problems), 비행(delinquent behavior), 공격성(aggressive behavior), 내재화 문제(internalizing problems), 외현화 문제 (externalizing problems), 총점(total score)이다. 이 척도에서 는 문제가 많을수록 점수가 높게 나타나는데, 환산점수인 $\mathrm{T}$ 점수 70점 이상을 임상범위로 보고 있다.

\section{3) 한국어판 학습장애평가척도(Korean version of Learning Disability Evaluation Scale, K-LDES)}

McCarney(1983)에 의해 개발된 LDES는 "미 공법 94 조 42 항”의 학습장애에 대한 정의를 토대로 개발된 88문항으로 이 루어진 척도이다. LDES는 1998년에 한국어판의 개발 및 표 준화가 이루어진 척도로 학습장애를 선별하고 의뢰된 학생들 의 학습장애 측정치를 제공하며 학습장애 진단에 기여할 수 있는 정보를 제공한다. ${ }^{16)}$ 확인된 문제영역에 도움이 되는 교 육활동들을 규명하여 교육활동 시작 시기와 교육활동의 결 과로 발생하는 경과를 기록하고, 만약 적합하다고 판명이 나 면 이러한 특수교육서비스제공을 중단할 시기를 결정하는데 에도 사용된다. 하위척도 표준점수는 7개의 요인(듣기, 사고력, 말하기, 읽기, 쓰기, 철자법, 수학)에 따라 군집으로 묶이는 학 습장애의 영역을 나타내는 것으로 학습장애에 대한 교육적 측 정치를 제공한다. K-LDES의 7개 하위척도는 곧 학습장애에 대해 7개영역으로 묶이는 요인을 나타내는 것이기도 하다. 학 습지수(Learning Quotient, LQ)는 7개 하위척도 평가치를 합 산한 점수를 평균이 100 이고 표준편차가 15 가 되도록 표준점 수로 전환한 것이다. 학습지수는 학습장애의 전반적인 측정 치로, $\mathrm{K}-\mathrm{LDES}$ 의 이론적인 구인으로 사용된 학습장애에 대 한 정의에 따라 학생이 성공적으로 수행할 수 있는지의 능력
을 나타내는 지표다.

4) 부모용 주의력결핍 과잉행동장애 평가척도(Korean version of Attention-Deficit/Hyperactivity Disorder Rating Scale, K-ARS)

ARS(ADHD Rating Scale-IV)는 학교 및 임상현장에서 $\mathrm{ADHD}$ 를 선별하는데 경제적이고 효율적인 도구로 알려져 있 다. DuPaul(1991)에 의해 개발된 이 도구는 학령기 아동의 $\mathrm{ADHD}$ 증상을 평가하기 위해 고안되었으며 국내에서 표준화 되어 사용되고 있다.17) $\mathrm{ARS}$ 는 $\mathrm{DSM}-\mathrm{IV}$ 의 $\mathrm{ADHD}$ 진단기준 으로 이루어진 총 18 문항으로 구성되어 있다. 각각의 문항은 아동의 문제행동의 빈도에 따라 '전혀 혹은 그렇지 않다' 0점, '때때로 그렇다' 1점, '자주 그렇다' 2점, '매우 자주 그렇다' 3점 으로 평정된다. 홀수 문항의 총점은 주의력결핍 증상을 측정 하며 짝수 문항의 총점은 과잉행동-충동성 증상을 측정하도 록 배열되어 있다.

$\operatorname{DuPaul}(1991)$ 은 ARS를 해석하는 데에 있어서 80th, 90th 백분위점수는 선별기준, $93 \mathrm{rd}$, 98th 백분위 점수는 검증기준 으로 사용할 수 있음을 제시한 바 있다. 김재원 등 ${ }^{18}$ 의 연구에 서 선별검사 기준으로 사용한 $\mathrm{ARS}$ 총점의 90th 백분위 절단 점수는 부모의 경우 19점, 교사의 경우 17점이었으며, 부모/교 사총점에서 모두 90th 백분위 절단점수 이상일 때 $\mathrm{ADHD}$ 진 단에 대한 양성 예측도(positive predictive value)가 0.85으로 나타나 지역사회에서 $\mathrm{ADHD}$ 를 효율적으로 판별해 낼 수 있 는 기준으로 사용될 수 있음을 제시하였다.

\section{5) 파탄적 행동장애평가척도(Disruptive Behavior Disorder Scale, DBDS) \\ $\mathrm{DSM}-\mathrm{IV}$ 의 주의력결핍 과잉행동장애(attention-deficit} hyperactivity disorder, $\mathrm{ADHD}$ ), 적대적 반항장애(oppositional defiant disorder, ODD), 품행장애(conduct disorder, $\mathrm{CD}$ )들의 진단 기준에 근거하여 부모가 아동의 행동에 대하 여 평가할 수 있도록 개발한 척도이다. 이 척도는 아직 한국 에서 표준화되지는 않았으나 여러 연구에서 아동의 행동 문 제에 대한 평가도구로 통상적으로 사용되고 있다. ${ }^{19)} \mathrm{DBDS}$ 는 $\mathrm{ADHD} 18$ 문항, $\mathrm{ODD}$ 8문항, $\mathrm{CD}$ 15문항으로 총 41문항으로 구성되어 있으나 본 연구에서는 $\mathrm{ODD}, \mathrm{CD}$ 에 해당하는 총 23 문항을 시행하였다. 각각의 문항은 '전혀 그렇지 않다' 0 점, '약 간 혹은 가끔 그렇다' 1점, '상당히 혹은 자주 그렇다' 2점, '매 우 자주 그렇다' 3점으로 평정된다.

\section{통계분석}

학년별 분포 및 남녀 비율에 대해서는 기술분석을 이용하 
였다. 소아수면습관설문의 내적 신뢰도를 평가하기 위하여 Cronbach의 알파를 계산하였다. 또한, 소아수면습관설문의 소척도간의 상관을 보기 위하여 Pearson 상관분석을 시행하 였다(Table 3). K-CBCL 총점 및 하위 항목, 부모용 ARS, 학 습장애척도, 파탄적행동평가척도와 소아수면습관설문의 소 척도 및 총점과의 상관을 보기 위하여 상관분석을 시행하였 다. 통계 프로그램은 SPSS version 17.0을 사용하였으며, 유 의수준은 $\mathrm{p}<.05$ 였다.

\section{결 과}

\section{1. 인구학적 특성}

대상자는 총 268명으로, 남아가 135명으로 전체 대상자의 $50.4 \%$ 를 차지하였으며, 여아가 133명으로 $49.6 \%$ 였다. 초등학 교 4학년은 94명, 5학년은 80명, 6학년은 94명이었다. 아버지의 학력은 중졸 이하가 $1.9 \%$, 고졸 $55.1 \%$, 초대졸 $11.4 \%$, 대졸 $29.3 \%$, 대졸이상 $2.3 \%$ 였다. 어머니의 학력은 중졸 이하가 $2.3 \%$, 고졸 $62.8 \%$, 초대졸 $15.3 \%$, 대졸 $18.8 \%$, 대졸 이상이 $0.8 \%$ 였다. 월수입이 200만원 미만인 경우가 $19.2 \%, 500$ 만원 이상
인 경우가 $14.7 \%$ 였다(Table 1).

주의력결핍 과잉행동장애 평가척도(ARS)의 총점평균은 $5.64 \pm 5.82$, 주의력결핍 점수평균은 $3.67 \pm 3.61$, 과잉행동 평균 은 $2.02 \pm 2.66$ 이었다. 파탄적 장애평가척도에서 적대적 반항 장애 소척도 점수의 평균은 $2.60 \pm 2.97$, 행실장애의 평균점 수는 $0.38 \pm 0.96$ 으로 평가되었다. $\mathrm{CBCL}$ 의 내재화 문제 T점 수의 평균은 $40.88 \pm 8.33$, 외현화 문제 T점수평균은 $40.92 \pm$ 7.92였다. K-LDES 학습지수의 평균은 $104.36 \pm 15.77$ 이었다. 이 척도들의 평균점수는 학교 간 유의한 차이는 없었다(Table 1).

소아수면습관 설문지(CSHQ)로 평가한 대상자의 수면 습관 및 소척도 간 상관이 연구에서 사용한 CSHQ의 Cronbach의 알파는 0.73 이었다. 입면저항 소척도의 평균과 표준편차 점수는 $9.18 \pm 2.17$ 점, 입면지연의 경우 $1.32 \pm 0.62$ 점, 수면량은 $4.19 \pm$ 1.52점, 수면불안은 $5.13 \pm 1.54$ 점, 입면후각성은 $3.37 \pm 0.78$ 점, 사건수면은 $8.21 \pm 1.42$ 점, 수면호흡장애는 $3.27 \pm 0.65$ 점, 주간 졸림은 $14.10 \pm 3.55$ 점으로 나타났다(Table 2). 또한, CSHQ 총 점과 입면 저항 $(r=0.59, p<.001)$, 입면지연 $(r=0.27, p<.001)$, 수 면량 $(r=0.38, p<.001)$, 수면불안 $(r=0.59, p<.001)$, 입면후각성 $(r=0.27, p<.001)$, 사건수면 $(r=0.54, p<.001)$, 수면호흡장애

Table 1. Clinical and demographic characteristics of participants

\begin{tabular}{|c|c|c|c|c|c|c|c|c|c|}
\hline & & \multicolumn{6}{|c|}{ School } & \multirow{2}{*}{\multicolumn{2}{|c|}{ Total }} \\
\hline & & \multicolumn{2}{|l|}{ A } & \multicolumn{2}{|l|}{ B } & \multicolumn{2}{|l|}{$C$} & & \\
\hline & & $\mathrm{n}$ & $\%$ & $n$ & $\%$ & $n$ & $\%$ & $n$ & $\%$ \\
\hline Gender & Grade & & & & & & & & \\
\hline \multirow[t]{4}{*}{ Boys } & $4^{\text {th }}$ grade & 16 & 32.0 & 16 & 37.2 & 18 & 42.9 & 50 & 37.0 \\
\hline & $5^{\text {th }}$ grade & 15 & 30.0 & 13 & 30.2 & 11 & 26.2 & 39 & 28.9 \\
\hline & $6^{\text {th }}$ grade & 19 & 38.0 & 14 & 32.6 & 13 & 31.0 & 46 & 34.1 \\
\hline & Total & 50 & 37.0 & 43 & 31.9 & 42 & 31.1 & 135 & 100 \\
\hline \multirow[t]{4}{*}{ Girls } & $4^{\text {th }}$ grade & 13 & 33.3 & 14 & 31.8 & 17 & 34.0 & 44 & 33.1 \\
\hline & $5^{\text {th }}$ grade & 11 & 28.2 & 14 & 31.8 & 16 & 32.0 & 41 & 30.8 \\
\hline & $6^{\text {th }}$ grade & 15 & 38.5 & 16 & 36.4 & 17 & 34.0 & 48 & 36.1 \\
\hline & Total & 39 & 29.3 & 44 & 33.1 & 50 & 37.6 & 133 & 100 \\
\hline \multicolumn{10}{|c|}{ Paternal educational years } \\
\hline & -6 & 4 & 4.7 & 1 & 1.2 & 0 & 0 & 5 & 1.9 \\
\hline & $7-9$ & 60 & 69.8 & 61 & 71.8 & 24 & 26.1 & 145 & 55.1 \\
\hline & $10-11$ & 9 & 10.5 & 8 & 9.4 & 13 & 14.1 & 30 & 11.4 \\
\hline & $12-13$ & 12 & 14.0 & 15 & 17.6 & 50 & 54.3 & 77 & 29.3 \\
\hline & $14-$ & 1 & 1.2 & 0 & 0 & 5 & 5.4 & 6 & 2.3 \\
\hline \multicolumn{10}{|c|}{ Maternal educational years } \\
\hline & -6 & 3 & 3.6 & 3 & 3.5 & 0 & 0 & 6 & 2.3 \\
\hline & $7-9$ & 63 & 75.0 & 65 & 76.5 & 36 & 39.1 & 164 & 62.8 \\
\hline & $10-11$ & 14 & 16.7 & 9 & 10.6 & 17 & 18.5 & 40 & 15.3 \\
\hline & $12-13$ & 4 & 4.8 & 6 & 7.1 & 39 & 42.4 & 49 & 18.8 \\
\hline & $14-$ & 0 & 0 & 2 & 2.4 & 0 & 0 & 2 & 0.8 \\
\hline \multicolumn{10}{|c|}{ Monthly income $(\$)$} \\
\hline & $-2,000$ & 17 & 19.1 & 26 & 30.6 & 8 & 8.7 & 51 & 19.2 \\
\hline & $2,000-$ & 72 & 80.9 & 59 & 69.4 & 84 & 91.3 & 215 & 80.8 \\
\hline
\end{tabular}


Table 1. Continued

\begin{tabular}{|c|c|c|c|c|c|c|c|c|c|}
\hline & & \multicolumn{6}{|c|}{ School } & \multirow{2}{*}{\multicolumn{2}{|c|}{ Total }} \\
\hline & & \multicolumn{2}{|l|}{ A } & \multicolumn{2}{|l|}{ B } & \multicolumn{2}{|l|}{ C } & & \\
\hline & & $\mathrm{n}$ & $\%$ & $\mathrm{n}$ & $\%$ & $\mathrm{n}$ & $\%$ & $\mathrm{n}$ & $\%$ \\
\hline & & Mean & SD & Mean & SD & Mean & SD & Mean & SD \\
\hline \multicolumn{10}{|l|}{ ARS } \\
\hline & Total score & 5.02 & 6.12 & 6.20 & 6.12 & 5.55 & 5.17 & 5.64 & 5.82 \\
\hline & Inattention & 3.35 & 3.80 & 4.06 & 3.83 & 3.63 & 3.23 & 3.67 & 3.61 \\
\hline & Hyperactivity-impulsivity & 1.98 & 2.96 & 2.10 & 2.63 & 1.98 & 2.41 & 2.02 & 2.66 \\
\hline \multicolumn{10}{|l|}{ DBDS } \\
\hline & Oppositional defiant disorder & 2.48 & 2.92 & 3.04 & 3.44 & 2.34 & 2.54 & 2.60 & 2.97 \\
\hline & Conduct disorder & .37 & 1.02 & .44 & 1.08 & .35 & .77 & .38 & .96 \\
\hline \multicolumn{10}{|c|}{$\mathrm{K}-\mathrm{CBCL}$} \\
\hline & Withdrawn & 42.16 & 12.37 & 43.56 & 11.59 & 42.29 & 10.37 & 42.65 & 11.44 \\
\hline & Somatic complaints & 44.16 & 6.03 & 44.17 & 6.15 & 44.30 & 6.53 & 44.21 & 6.21 \\
\hline & Anxious depressed & 43.46 & 8.27 & 43.27 & 7.49 & 41.25 & 7.07 & 42.66 & 7.67 \\
\hline & Social problem & 45.13 & 8.59 & 46.16 & 8.25 & 44.41 & 6.73 & 45.22 & 7.90 \\
\hline & Thought problem & 46.91 & 5.33 & 46.82 & 5.01 & 46.65 & 3.95 & 46.79 & 4.78 \\
\hline & Attention problem & 42.26 & 7.82 & 42.69 & 9.26 & 40.96 & 6.30 & 41.96 & 7.87 \\
\hline & Delinquent behavior & 44.71 & 6.56 & 45.00 & 5.57 & 44.68 & 5.30 & 44.79 & 5.82 \\
\hline & Aggressive behavior & 41.04 & 8.40 & 42.30 & 8.28 & 40.34 & 6.83 & 41.21 & 7.88 \\
\hline & Internalizing problems & 41.16 & 8.67 & 41.95 & 8.00 & 40.09 & 6.98 & 40.92 & 7.92 \\
\hline & Externalizing problems & 40.78 & 8.668 & 41.95 & 8.00 & 40.09 & 6.98 & 40.92 & 7.92 \\
\hline & Total problematic behavior & 39.56 & 9.89 & 40.34 & 9.22 & 39.31 & 7.49 & 39.73 & 8.91 \\
\hline \multicolumn{10}{|c|}{ K-LEDS } \\
\hline & Listening & 9.60 & 2.42 & 9.05 & 2.79 & 9.29 & 2.84 & 9.31 & 2.69 \\
\hline & Thinking & 10.11 & 2.00 & 9.25 & 3.25 & 9.52 & 2.80 & 9.63 & 2.74 \\
\hline & Speaking & 10.24 & 2.63 & 8.74 & 3.94 & 9.29 & 3.69 & 9.43 & 3.51 \\
\hline & Reading & 10.54 & 2.73 & 9.39 & 3.33 & 9.97 & 2.90 & 9.97 & 3.03 \\
\hline & Writing & 11.45 & 3.58 & 1078 & 4.46 & 11.25 & 3.43 & 11.16 & 3.85 \\
\hline & Spelling & 11.12 & 2.99 & 11.18 & 2.93 & 11.26 & 2.30 & 11.19 & 2.75 \\
\hline & Mathematical calculation & 15.17 & 5.59 & 14.59 & 6.37 & 15.13 & 5.73 & 15.00 & 5.88 \\
\hline & Learning quotient & 106.56 & 13.18 & 101.83 & 16.90 & 104.64 & 16.83 & 104.36 & 15.77 \\
\hline
\end{tabular}

ARS : ADHD Rating Scale, DBDS : Disruptive Behavior Disorder Scale, CBCL : Child Behavior Checklist, K-LEDS : Korean version of Learning Disability Evaluation Scale, ADHD : attention-deficit hyperactivity disorder

Table 2. Comparison of reported sleep patterns based on CSHQ subscales between Current and Owen's study

\begin{tabular}{|c|c|c|c|c|c|c|c|c|c|}
\hline & \multicolumn{3}{|c|}{ Current study } & \multicolumn{6}{|c|}{ Owen's study ${ }^{12)}$} \\
\hline & \multirow[b]{2}{*}{$\mathrm{N}$} & \multirow[b]{2}{*}{ Mean } & \multirow[b]{2}{*}{ SD } & \multicolumn{3}{|c|}{ Control sample } & \multicolumn{3}{|c|}{ Clinic sample } \\
\hline & & & & $\mathrm{N}$ & Mean & SD & $\mathrm{N}$ & Mean & SD \\
\hline Bedtime resistance* & 235 & 9.18 & 2.17 & 382 & 7.06 & 1.89 & 128 & 9.43 & 3.49 \\
\hline Sleep onset delay & 250 & 1.32 & 0.62 & 403 & 1.25 & 0.53 & 128 & 1.80 & 0.88 \\
\hline Sleep duration* & 233 & 4.19 & 1.52 & 398 & 3.41 & 0.93 & 122 & 4.94 & 1.98 \\
\hline Sleep anxiety & 244 & 5.13 & 1.54 & 374 & 4.89 & 1.45 & 119 & 7.09 & 2.44 \\
\hline Night wakings & 240 & 3.37 & 0.78 & 384 & 3.51 & 0.89 & 120 & 5.69 & 1.60 \\
\hline Parasomnias & 241 & 8.21 & 1.42 & 371 & 8.11 & 1.25 & 117 & 11.22 & 2.53 \\
\hline Sleep disordered breathing & 247 & 3.27 & 0.65 & 382 & 3.24 & 0.63 & 17 & 4.71 & 2.54 \\
\hline Daytime sleepiness*† & 216 & 14.10 & 3.55 & 381 & 9.64 & 2.80 & 119 & 11.99 & 3.39 \\
\hline
\end{tabular}

$*: p<.001$ compared with control group of Owen's study, $\dagger: p<.001$ compared with clinic group of Owen's study. $N$ : number, SD : standard deviation, CSHQ : Child's Sleep Habit Questionnaire 
$(\mathrm{r}=0.32, \mathrm{p}<.001)$, 주간졸림 $(\mathrm{r}=0.73, \mathrm{p}<.001)$ 는 모두 통계적으 로 유의한 상관이 있었다. 또한 입면저항과 수면불안의 상관 $(\mathrm{r}=0.73, \mathrm{p}<.001)$ 은 매우 높았으며, 입면저항과 입면지연도 상 관(r=0.35, $\mathrm{p}<.001)$ 을 보였다(Table 3).

소아수면습관 설문지와 한국어판 부모용 아동행동평가척 도 입면저항(Bedtime resistance)은 위축(r=0.17, p=.01), 신 체증상 $(\mathrm{r}=0.14, \mathrm{p}=.05)$, 불안/우울 $(\mathrm{r}=0.22, \mathrm{p}=.001)$, 사회적 미 성숙 $(\mathrm{r}=0.19, \mathrm{p}=.004)$, 주의집중 문제 $(\mathrm{r}=0.234, \mathrm{p}<.001)$, 비행 $(\mathrm{r}=0.152, \mathrm{p}=.02)$, 공격성 $(\mathrm{r}=0.21, \mathrm{p}=.001)$, 내재화 문제 $(\mathrm{r}=0.24$, $\mathrm{p}<.001)$, 외현화 문제 $(\mathrm{r}=0.21, \mathrm{p}=.002)$ 와 유의한 상관이 있었 다(Table 4).

입면지연(Sleep onset delay)은 사회적 미성숙 $(\mathrm{r}=0.16$, $\mathrm{p}=0.01)$, 비행 $(\mathrm{r}=0.15, \mathrm{p}=.02)$ 과 상관을 보였다. 또한 수면량 (sleep duration)은 신체증상 $(\mathrm{r}=0.19, \mathrm{p}=.01)$, 불안/우울 $(\mathrm{r}=0.22, \mathrm{p}=.001)$, 주의집중 문제 $(\mathrm{r}=0.15, \mathrm{p}=.03)$, 비행 $(\mathrm{r}=0.14$, $\mathrm{p}=.04)$, 공격성( $\mathrm{r}=0.21, \mathrm{p}=.002)$, 내재화 문제 $(\mathrm{r}=0.22, \mathrm{p}=.001)$, 외현화 문제 $(\mathrm{r}=0.21, \mathrm{p}=.002)$ 와 유의한 상관을 보였다. 한편, 수면불안(sleep anxiety)은 위축 $(\mathrm{r}=0.24, \mathrm{p}<.001)$, 신체증상 $(\mathrm{r}=0.20, \mathrm{p}=.002)$, 불안/우울 $(\mathrm{r}=0.30, \mathrm{p}<.001)$, 사회적 미성숙 $(\mathrm{r}=0.24, \mathrm{p}<.001)$, 사고의 문제 $(\mathrm{r}=0.18, \mathrm{p}=.01)$, 주의집중 문제 $(\mathrm{r}=0.28, \mathrm{p}<.001)$, 공격성 $(\mathrm{r}=0.17, \mathrm{p}=.01)$, 내재화 문제 $(\mathrm{r}=0.33$, $\mathrm{p}<.001)$, 외현화 문제 $(\mathrm{r}=0.17, \mathrm{p}=.01)$ 와 유의한 상관이 있었고, 입면후각성(Night waking)은 사고장애( $\mathrm{r}=0.16, \mathrm{p}=.02)$, 비행 $(r=0.20, p=.003)$ 과 유의한 상관을 보였다.

사건수면(parasomnias)은 신체증상 $(r=0.21, p=.001)$, 불안/ 우울 $(\mathrm{r}=0.19, \mathrm{p}=.004)$, 사고의 문제 $(\mathrm{r}=0.09, \mathrm{p}=.02)$, 주의집중 문 제 $(\mathrm{r}=0.19, \mathrm{p}=.01)$, 비행 $(\mathrm{r}=0.22, \mathrm{p}=.01)$, 내재화 문제 $(\mathrm{r}=0.22$, $\mathrm{p}=.001)$, 외현화 문제( $\mathrm{r}=0.17, \mathrm{p}=.01)$ 와 유의한 상관이 있었다. 수면호흡장애(Sleep disordered breathing)는 사고의 문제 $(\mathrm{r}=0.19, \mathrm{p}=.02)$, 사회적 미성숙 $(\mathrm{r}=0.16, \mathrm{p}=.004)$, 주의집중 문제 $(\mathrm{r}=0.15, \mathrm{p}=.02)$ 와 유의하였으며, 주간졸림(daytime sleepiness)은 위축 $(r=0.19, \mathrm{p}=.01)$, 불안/우울( $(\mathrm{r}=0.19, \mathrm{p}=.01)$, 주의집 중 문제 $(\mathrm{r}=0.25, \mathrm{p}<.001)$, 비행 $(\mathrm{r}=0.17, \mathrm{p}=.02)$, 공격성 $(\mathrm{r}=0.32$, $\mathrm{p}<.001)$, 내재화 문제 $(\mathrm{r}=0.23, \mathrm{p}=.001)$, 외현화 문제 $(\mathrm{r}=0.30$, $\mathrm{p}<.001$ )와 상관이 있었다(Table 4).

소아수면습관 설문지와 부모용 주의력결핍 과잉행동장애 평가척도 입면저항은 과잉행동 $(\mathrm{r}=0.14, \mathrm{p}=.04)$ 와 유의한 상관 이 있으며 수면불안은 주의력결핍 $(\mathrm{r}=0.13, \mathrm{p}=.05)$, 과잉행동

Table 3. Intercorrelation matrix among CSHQ subscales

\begin{tabular}{|c|c|c|c|c|c|c|c|c|c|}
\hline CSHQ subscales & 1 & 2 & 3 & 4 & 5 & 6 & 7 & 8 & 9 \\
\hline 1. Bedtime resistance & 1 & $.35^{\dagger}$ & $.16^{*}$ & $.73^{\dagger}$ & .02 & $.13^{*}$ & -.05 & .13 & $.59^{\dagger}$ \\
\hline 2. Sleep onset delay & & 1 & .38 & .06 & .03 & -.05 & -.10 & -.12 & $.27^{\dagger}$ \\
\hline 3. Sleep duration & & & 1 & .07 & .01 & -.02 & -.05 & .05 & $.38^{\dagger}$ \\
\hline 4. Sleep anxiety & & & & 1 & .10 & $.25^{\dagger}$ & .05 & $.22^{\dagger}$ & $.59^{\dagger}$ \\
\hline 5. Night wakings & & & & & 1 & $.30^{\dagger}$ & $.32^{\dagger}$ & -.04 & $.27^{\dagger}$ \\
\hline 6. Parasomnias & & & & & & 1 & $.42^{\dagger}$ & $.26^{\dagger}$ & $.54^{\dagger}$ \\
\hline 7. SDB & & & & & & & 1 & .13 & $.32^{\dagger}$ \\
\hline 8. Daytime sleepiness & & & & & & & & 1 & $.73^{+}$ \\
\hline 9. Total score & & & & & & & & & 1 \\
\hline
\end{tabular}

$*: p<.05, \dagger: p<.005$. SDB : sleep disordered breathing, CSHQ : Child's Sleep Habit Questionnaire

Table 4. Correlation between subscales of $\mathrm{CSHQ}$ and $\mathrm{CBCL}$

\begin{tabular}{|c|c|c|c|c|c|c|c|c|c|c|c|}
\hline $\mathrm{CSHQ} \quad \mathrm{CBCL}$ & Withdrawn & $\begin{array}{l}\text { Somatic } \\
\text { complaints }\end{array}$ & $\begin{array}{c}\text { Anxious } \\
\text { depressed }\end{array}$ & $\begin{array}{l}\text { Social } \\
\text { problem }\end{array}$ & $\begin{array}{l}\text { Thought } \\
\text { problem }\end{array}$ & $\begin{array}{l}\text { Attention } \\
\text { problem }\end{array}$ & $\begin{array}{c}\text { Delinquent } \\
\text { behavior }\end{array}$ & $\begin{array}{l}\text { Aggressive } \\
\text { behavior }\end{array}$ & $\begin{array}{c}\text { Internalizing } \\
\text { problems }\end{array}$ & $\begin{array}{c}\text { Externalizing } \\
\text { problems }\end{array}$ & Total \\
\hline $\begin{array}{l}\text { Bedtime } \\
\text { resistance }\end{array}$ & $.17^{\dagger}$ & $.14^{*}$ & $.22^{\dagger}$ & $.19^{\dagger}$ & .09 & $.23^{\dagger}$ & $.15^{*}$ & $.21^{\dagger}$ & $.24^{\dagger}$ & $.21^{\dagger}$ & $.26^{\dagger}$ \\
\hline $\begin{array}{l}\text { Sleep onset } \\
\text { delay }\end{array}$ & .01 & -.08 & .08 & $.16^{*}$ & .02 & .09 & $.15^{*}$ & .09 & .06 & .11 & .11 \\
\hline Sleep duration & .04 & $.19^{\dagger}$ & $.22^{\dagger}$ & .13 & .08 & $.15^{*}$ & $.14^{*}$ & $.21^{\dagger}$ & $.22^{\dagger}$ & $.21^{\dagger}$ & $.23^{\dagger}$ \\
\hline Sleep anxiety & $.24^{\dagger}$ & $.20^{\dagger}$ & $.30^{\dagger}$ & $.24^{\dagger}$ & $.18^{\dagger}$ & $.28^{\dagger}$ & .12 & $.17^{\dagger}$ & $.33^{\dagger}$ & $.17^{\dagger}$ & $.29^{\dagger}$ \\
\hline Night wakings & -.02 & .10 & .09 & .10 & $.16^{*}$ & .09 & $.20^{\dagger}$ & .07 & .09 & .13 & $.13^{*}$ \\
\hline Parasomnias & .10 & $.21^{\dagger}$ & $.19^{\dagger}$ & $.16^{*}$ & .09 & $.19^{\dagger}$ & $.22^{\dagger}$ & .13 & $.22^{\dagger}$ & $.17^{*}$ & $.24^{\dagger}$ \\
\hline $\begin{array}{l}\text { Sleep disordered } \\
\text { breathing }\end{array}$ & .09 & .05 & .12 & $.16^{*}$ & $.19^{\dagger}$ & $.15^{*}$ & .11 & .04 & .10 & .08 & $.14^{*}$ \\
\hline $\begin{array}{l}\text { Daytime } \\
\text { sleepiness }\end{array}$ & $.19^{\dagger}$ & .12 & $.19^{\dagger}$ & $.20^{\dagger}$ & .12 & $.25^{\dagger}$ & $.17^{*}$ & $.32^{\dagger}$ & $.23^{\dagger}$ & $.30^{\dagger}$ & $.31^{\dagger}$ \\
\hline Total score & $.24^{\dagger}$ & $.24^{\dagger}$ & $.38^{\dagger}$ & $.33^{\dagger}$ & $.21^{\dagger}$ & $.39^{\dagger}$ & $.35^{\dagger}$ & $.41^{\dagger}$ & $.41^{\dagger}$ & $.43^{\dagger}$ & $.48^{\dagger}$ \\
\hline
\end{tabular}

$*: p<0.05, \dagger: p<0.005$. CSHQ : Child's Sleep Habit Questionnaire, CBCL : Child Behavior Checklist 
$(\mathrm{r}=0.19, \mathrm{p}=.003)$ 총점 $(\mathrm{r}=0.16, \mathrm{p}=.02)$ 과 유의한 상관이 있는 것으로 나타났다. 사건수면의 경우 과잉행동 $(\mathrm{r}=0.15, \mathrm{p}=.02)$ 과 상관을 보였다. 주간졸림은 주의력저하 $(\mathrm{r}=0.22, \mathrm{p}=.002)$, 과잉 행동 $(\mathrm{r}=0.22, \mathrm{p}=.001)$, 총점 $(\mathrm{r}=0.22, \mathrm{p}=.001)$ 과 상관이 있는 것 으로 나타났다(Table 5).

\section{2. 소아수면습관 설문지와 파탄적 장애평가척도}

$\mathrm{CSHQ}$ 와 $\mathrm{DBDS}$ 의 연관을 살펴보면 적대적 반항장애 증상 과 관련된 수면습관 하위척도로는 입면저항 $(\mathrm{r}=0.15, \mathrm{p}=.03)$, 수 면불안 $(\mathrm{r}=0.13, \mathrm{p}=.04)$, 사건수면 $(\mathrm{r}=0.21, \mathrm{p}=.001)$, 주간졸림 $(\mathrm{r}=0.23, \mathrm{p}=.001)$ 이 유의한 상관을 보였다. 또한, 행실장애척도 점수와 입면후각성 $(\mathrm{r}=0.16, \mathrm{p}=.02)$, 사건수면( $\mathrm{r}=0.21, \mathrm{p}=.02)$, 수 면호흡장애 $(r=0.31, p<.001)$, 주간졸림 $(r=0.27, p<.001)$ 이 유의 한 상관을 보였다(Table 5).

\section{3. 소아수면습관 설문지와 학습장애평가척도의 상관관계}

입면지연과 수면량은 학습 문제와 상관이 있는 것으로 나 타났다. 입면지연은 사고력 $(\mathrm{r}=-0.17, \mathrm{p}=.01)$, 말하기 $(\mathrm{r}=-0.18$, $\mathrm{p}=.01)$, 읽기 $(\mathrm{r}=-0.15, \mathrm{p}=.03)$, 철자법 $(\mathrm{r}=-0.15, \mathrm{p}=.03)$, 수학 $(\mathrm{r}=-0.17, \mathrm{p}=.01)$ 과 상관관계가 있었고, 수면량은 사고력 $(\mathrm{r}=0.17, \mathrm{p}=.02)$ 과 통계적으로 유의한 상관을 보였다(Table 6).

\section{고 찰}

본 연구는 학령기 초등학생들에서 수면 문제와 행동, 정서, 주의력, 학습능력 저하의 연관성을 보고한 연구이다. 수면습 관 문제는 전반적인 행동 문제, 주의력과도 관련을 보였고, 특 히 늦은 취침시간과 수면량 부족은 학습 문제 중에서도 사고 력, 읽기, 철자법, 수학과 상관이 있었다.

본 연구에서 나타난 우리나라 아동의 수면습관의 특징을 선행연구와 비교하여 보면, 본 연구의 결과는 최지애 등 ${ }^{13)}$ 이 보고한 우리나라 아동의 수면습관 설문지 점수와 유사한 점 수를 보였다. 아동수면습관 설문지를 개발한 원저자 Owen ${ }^{12)}$ 이 2000년에 보고한 미국 뉴잉글랜드 지역연구의 정상 대조 군과 본 연구대상군의 수면습관 설문지점수를 비교했을 때 본 연구대상군이 입면저항, 수면량, 주간졸림의 소척도에서 유의하게 높은 점수 $(\mathrm{p}<.0001)$ 를 보였다(Table 2). 또한 Owen

Table 5. Correlation between reported sleep problem in CSHQ, attentional problems in ARS and behavioral problems in DBDS

\begin{tabular}{|c|c|c|c|c|c|}
\hline \multirow[t]{2}{*}{ CSHQ subscales } & \multicolumn{3}{|c|}{ ARS } & \multicolumn{2}{|c|}{ DBDS } \\
\hline & Inattention & $\mathrm{HI}$ & Total & ODD & Conduct disorder \\
\hline Bedtime resistance & .10 & $.14^{*}$ & .11 & $.15^{*}$ & .05 \\
\hline Sleep onset delay & .00 & .02 & .00 & -.03 & .05 \\
\hline Sleep duration & .08 & .08 & .08 & -.03 & .13 \\
\hline Sleep anxiety & $.13^{*}$ & $.19^{\dagger}$ & $.16^{*}$ & $.13^{*}$ & .05 \\
\hline Night wakings & .04 & .10 & .07 & $.14^{*}$ & $.16^{*}$ \\
\hline Parasomnias & .11 & $.15^{*}$ & .12 & $.21^{\dagger}$ & $.21^{\dagger}$ \\
\hline Sleep disordered breathing & .11 & .10 & .10 & .09 & $.31^{\dagger}$ \\
\hline Daytime sleepiness & $.22^{\dagger}$ & $.22^{\dagger}$ & $.22^{\dagger}$ & $.23^{\dagger}$ & $.15^{*}$ \\
\hline Total score & $.23^{\dagger}$ & $.32^{\dagger}$ & $.27^{\dagger}$ & $.28^{\dagger}$ & $.27^{\dagger}$ \\
\hline
\end{tabular}

$*: \mathrm{p}<.05 . \dagger: \mathrm{p}<.005$. CSHQ : Child's Sleep Habit Questionnaire, ARS : Adhd Rating Scale, DBDS : the Disruptive Behavior Disorder Scale, HI : hyperactivity-impulsivity, ODD : oppositional defiant disorder

Table 6. Correlation between reported sleep problems in CSHQ and learning problems in K-LEDS

\begin{tabular}{|c|c|c|c|c|c|c|c|c|}
\hline K-LEDS & Listening & Thinking & Speaking & Reading & Writing & Spelling & $\begin{array}{l}\text { Mathemati- } \\
\text { cal calcula- } \\
\text { tion }\end{array}$ & $L Q$ \\
\hline Bedtime resistance & -.06 & -.05 & -.09 & -.03 & .07 & .03 & -.06 & -.03 \\
\hline Sleep onset delay & -.05 & $-.17^{*}$ & $-.18^{* *}$ & $-.15^{*}$ & -.07 & $-.15^{*}$ & $-.17^{*}$ & $-.19^{\dagger}$ \\
\hline Sleep duration & -.04 & $-.17^{*}$ & -.02 & -.07 & -.05 & -.13 & -.07 & -.11 \\
\hline Sleep anxiety & -.01 & .00 & -.11 & -.05 & .08 & .05 & .01 & .01 \\
\hline Night wakings & -.02 & .01 & -.08 & -.07 & -.01 & -.08 & -.03 & -.05 \\
\hline Parasomnias & .00 & -.01 & -.03 & -.07 & -.02 & .00 & -.05 & -.04 \\
\hline Sleep disordered breathing & .04 & -.01 & -.01 & -.06 & -.04 & .00 & .04 & .01 \\
\hline Daytime sleepiness & -.06 & -.05 & .05 & .02 & .06 & .01 & .02 & .02 \\
\hline Total score & -.09 & -.13 & -.09 & -.13 & .04 & -.06 & -.08 & -.10 \\
\hline
\end{tabular}

* : $\mathrm{p}<.05, \dagger: p<.005$. haracteristics of Participants CSHQ : Child's Sleep Habit Questionnaire, K-LEDS : Korean Version of Learning Disability Evaluation Scale, LQ : learning quotient 
의 연구에서 수면 문제가 있었던 군의 점수와 본 연구에서의 점수를 비교해 보면, 대부분의 소척도에서 Owen 연구 내 임 상군의 소척도 점수가 유의 $(\mathrm{p}<.001)$ 하게 높았으나, Owen 연 구의 임상군과 본 연구대상군의 입면저항 점수는 차이가 없 었다(p=.23). 양국의 척도의 평균점수를 직접 비교하기에는 문화적 차이를 고려한 설문지의 표준화 작업 및 양국 비교연 구가 선행되어야 할 것이다. 그렇지만, 수면량(sleep duration)의 경우 아시아의 어린이가 서양의 어린이에 비해 상대적 으로 총수면량이 적다는 보고 ${ }^{20}$ 와, 세계 17 개국 수면양의 비 교연구에서 우리나라가 일본에 이어 3 위로 총 수면량이 적다 는 보고'를 감안한다면, 이 결과는 우리나라 아동의 수면이 충분히 보장받지 않고 있을 가능성을 시사한다. 또한 우리나 라에서는 학년이 올라가면서 학습 등의 부담으로 수면 시간 이 보장받기 어려우며, 이에 따라 주간졸림과 우울감 증가가 보고된 바 있다. ${ }^{8)}$ 본 연구대상군의 주간졸림 평균점수(14.10 $\pm 3.55)$ 는 Owen 연구의 대조군(9.64 $\pm 2.80, \mathrm{p}<.001)$ 보다 높 았을 뿐 아니라, 수면장애 클리닉 환자군의 평균 점수(11.99 $\pm 3.39, \mathrm{p}<.001)$ 보다도 유의하게 높았다. 우리나라 아동들이 수면시간이 부족하고, 주간졸림증상이 외국보다 더 높을 가 능성을 염두에 둔다면, 이로 인한 낮 동안의 각성 상태나 인지 기능 및 정서에 미칠 부정적인 영향을 고려할 때, 보다 더 많 은 아동을 대상으로 실태 파악을 시행하여 개입의 필요성에 대하여 확인하는 것이 초등학생의 정신건강 증진에 중요한 부분이 될 수 있을 것으로 보인다.

수면과 아동의 행동문제와의 관련성을 살펴보면 아동행동 평가척도의 총 문제행동 점수가 소아수면습관 설문에서 입 면지연을 제외한 전 영역 즉 입면저항, 수면량, 수면불안, 입면 후각성, 사건수면, 수면호흡장애, 주간 졸림 및 총점과 유의 한 양의 상관이 있었다. 또한 비행, 공격성, 외현화 문제 등도 소아수면습관설문의 총점과 유의한 상관이 있었고 $\mathrm{CBCL}$ 의 다양한 소척도에서도 유의한 상관을 보였다. 유사하게, 파탄 적행동평가척도의 점수와 소아수면습관 설문지의 총점 및 여 러 소척도에서 유의한 상관이 있었다. 이는 청소년의 수면 문 제가 지각과 결석, 사고나 손상의 문제와 관련이 있다는 Carskadon 등 ${ }^{6}$ 의 연구나 수면을 잘 취하는 아동에 비하여 수면 을 잘 취하지 못 하는 아동이 아동행동평가척도에서 총 문제 행동, 비행행동에서 유의한 차이를 보였다는 Sadeh 등ㄲㅇㅢ 연 구, 그리고 수면 문제와 행동장애와 가족 내 여러 가지 문제 가 관련이 있다는 보고 ${ }^{21)}$ 와도 일치한다 따라서 우리나라 아 동에서도 수면 문제가 전반적인 행동문제 및 비행과 관련이 있을 수 있음을 시사한다.

손광국 등 22 은 수면장애가 있는 경우, $29.4 \%$ 가 불안증, $47.1 \%$ 가 우울증을 의심할 수 있으며, 기분장애가 동반되기도
하여 정서문제에 대한 적극적인 진단과 치료가 필요함을 보 고하였다. 안호영 등 23$)$ 은 2,965명의 우리나라 청소년을 대상으 로 한 연구에서 수면 부족이 있을 때 자살사고의 위험이 1.43 배 증가함( $\mathrm{p}=.009)$ 을 보고하였다. 마찬가지로, 서혜은 등 21$)$ 은 2 16세의 소아청소년 32명에 대한 연구에서 수면장애 집단에 서 다면적 인성검사의 강박, 우울척도가 상승하였다고 보고하 였다. 이 연구에서도 아동행동평가척도의 위축, 신체화, 불안 우울, 내재화 문제가 수면습관설문의 총점과 유의한 상관이 있었다. 이는 수면 문제가 우울 및 불안등과 같은 정서적인 면 과 관련될 가능성에 대한 기존의 연구 결과와 일치한다.

수면과 주의력은 서로 상호적인 영향을 미치는 것으로 생 각되는데 양적, 질적으로 정상적인 수면이 박탈되면 사고나 실수의 가능성이 증가하고 주의 집중력 및 판단력에 부정적 인 영향을 미친다. ${ }^{24)}$ 우리나라에서 수면장애 아동의 $11.4 \%$ 에 서 주의력저하가 있고, $6.8 \%$ 에서 과잉행동이 있다는 보고 ${ }^{25}$ 가 있으며, 수면호흡장애 환아에서 주의력저하, 자기조절능력의 저하 ${ }^{26)}$ 가 보고된 바 있다. 반면 주의력결핍 과잉행동장애 아 동에서 입면의 어려움, 잦은 각성, 기상시 피곤함, 각성 후 입 면의 어려움, 수면호흡장애, 사건수면 등이 보고 ${ }^{27}$ 되고 있다. 본 연구에서 소아수면습관척도의 총점 및 수면불안, 주간졸 림 문항 점수가 부모용 ARS의 총점 및 과잉행동, 부주의 점 수와 모두 유의한 상관을 보였다. 이는 이전 연구들 중 수면습 관의 변화가 일과 중에 미치는 집중력, 주의력유지에 부정적 인 영향을 미친다고 보고한 연구 ${ }^{25,28}$ 와 일치한다

수면과 학습과의 관계를 살펴보면, 정상적인 수면이 박탈되 면 소아에서 학습과 기억력에 부정적인 영향을 미치는 것으 로 알려져 있다.) 우리나라에서도 소아청소년 수면장애 환자 의 $5.7 \%$ 에서 학습장애증상을 보고하고 있다. ${ }^{25)}$ 본 연구에서 는 잠자리에 들어 20 분내에 수면을 취하지 못하는 입면지연 소항목이 사고력, 읽기, 철자법, 수학적 계산능력의 저하와 연 관되는 것으로 나타났다. Carskadon의 연구에 의하면, 주중 보다 주말에 늦게 자는 수면패턴이 주중의 학습 능력 저하와 연관된다고 하였는데 ${ }^{6}$ 본 연구에서도 이에 해당하는 소척도 인 입면 지연이 학습에 부정적인 영향을 미치는 것을 볼 수 있었다. 입면지연은 낮동안의 각성상태에서 수면상태로 전환 되는 것이 어려운 것을 의미하는 것인데, TV시청, 인터넷 사 용, 게임, 핸드폰 사용, 늦은 시간까지 이어지는 학업 등이 이 의 원인이 되었을 가능성이 있다. ${ }^{7,29}$

$\mathrm{K}-\mathrm{LDES}$ 의 사고력 소척도는 기억력, 시· 공간적 능력, 계기 적 정보처리능력을 평가하는데, 본 연구에서는 수면량과 $\mathrm{K}-$ $\mathrm{LDES}$ 의 사고력 소척도는 음의 상관을 보였다. 이는, 수면량 감소가 학습능력 저하나 신경행동 수행능력의 저하와 연관 된다는 Carskadon, Sadeh의 보고 ${ }^{67}$ 와 일치하는 결과이다. 
낮 동안의 각성과 적절한 수행에 충분한 양의 수면을 일정한 시간대에 취하는 것이 필수적이다.) 또한, 학습 후의 수면이 기억을 강화시키고, 새로운 기억의 등록을 위해서는 학습 전 의 수면이 중요한 역할을 한다. ${ }^{30)}$ 따라서 장기간의 수면의 부 족 및 박탈은 기억 등록 및 장기기억이 필수적인 학습수행 능 력이 부정적인 영향을 미칠 수 있다. Goza ${ }^{12)}$ 는 수면장애를 치료하여 학습성취가 증진되는 것을 보고하고 있는데 수면 문 제가 학습의 문제와 관련이 있다고 하면, 이의 개선이 발달 중인 아동의 학습능력을 향상시킬 수도 있을 것으로 생각된다.

본 연구는 횡단연구라는 방법상의 문제로 인해, 수면 문제 가 있는 아동의 행동 및 주의력, 학습 문제가 수면 문제에 따 른 이차적인 결과인지 판단할 수 없다는 제한점을 가진다. 그 러나 현재까지 우리나라 지역사회 일반아동을 대상으로 수 면 문제를 세분하여 행동 및 주의력, 그리고 학습 문제와 관 련된 보고가 없어 이를 확인하는데 의의가 있다. 향후 수면 문제와 연관될 수 있는 아동의 인지행동 정서학습 문제 등의 인과관계를 파악하기 위한 전향적인 연구가 필요할 것으로 판 단된다.

또한, 수면에 대한 평가를 보호자의 보고에 의한 설문을 통 한 평가만을 사용하였다. 설문을 통한 평가에는 보호자의 기 억, 수면 문제에 대한 인식도 등에 따라 회상 편견이 생길 수 있고, 수면에 대한 사회 문화적 관점, 주관적인 수면의 측정과 객관적인 수면의 장애 정도가 일치하지 않는다는 연구결과 등 ${ }^{13,20)}$ 이 설문지를 통한 수면평가의 제한점을 언급하고 있다. 추후 지역사회 아동을 대상으로 수면다원검사와 같은 검사를 통한 보다 객관적인 평가를 시행하면서 수면과 심리사회적인 면과의 관련성을 연구할 필요도 있을 것으로 생각된다. 그럼 에도 불구하고, 기존의 우리나라의 소아수면에 대한 연구에 서 수면의 다양한 단계에 대한 체계적인 조사가 부족하였던 기존 연구와 달리 22,25$)$ 수면 문제의 여러 가지 세부항목을 $\mathrm{CSHQ}$ 라는 표준화된 방법을 기준으로 구체적인 수면의 질 및 수면 문제를 평가하였다는 점에서 그 의의를 갖는다고 할 수 있다. 향후 이 도구의 국내 표준화도 이루어져야 할 것으로 보인다.

셋째로, 연구대상이 일 도시 지역 내 3개 학교로 제한되어 있으므로 지역적, 경제적, 문화적 특성으로 인해 선택 편견이 존재했을 가능성이 있다. 수면시간 및 수면질환은 인종적, 문화적, 지역적 특성에 따라 많은 차이가 존재해 왔으며, 같은 문화권 내에서도 주거 환경에 따른 차이의 가능성도 배제할 수 없다. 서완석 등이 보고한 대구지역 내 3,639명의 초등학생 의 수면양상에 대한 연구결과에 따르면, 아파트에 거주하고, 사교육 활동, 티브이 시청 및 컴퓨터 사용시간이 높을수록 총 수면시간이 적은 것을 보고 하고 있다. ${ }^{11)}$ 이처럼 한 지역 내에
서도 사회문화적 요소에 따라 수면양상이 달라질 수 있으므 로 추후 전국의 여러 지역으로 확대한 추가 연구를 시행할 필 요가 있을 것으로 보인다.

넷째로 대상군이 처해 있는 사회문화적 환경에 대한 평가 나 수면 문제가 다른 의학적인 상태나 정신병리적인 증상의 일부일 가능성에 대해서 충분한 평가가 이루어지지 못했다. 연구대상군에 대한 정서 및 사고 평가를 통해서 아동이 현재 겪고 있는 수면 문제에 영향을 줄 수 있는 의학적 혹은 정신병 리적 요인, 사회문화적 환경에 대한 평가가 후속 연구에서는 보충되어야 할 것이다.

이와 같은 제한점에도 불구하고, 본 연구는 소아에서의 수 면습관의 문제가 행동, 정서, 학습 등과 관련성이 있다는 것을 확인했다는 점에서 의의가 있다. 추후 더 많은 아동을 대상으 로 하여 수면습관 및 이와 연관될 것으로 추정되는 수면 시 간과 환경적인 요소를 탐색하는 추가적이 연구들이 필요할 것으로 생각된다.

\section{결 론}

지역사회 내 10 12세 초등학생 268명을 대상으로 수면습 관 및 학습, 행동, 정서, 주의력 등에 대하여 설문지를 통해 조 사하였다. 이 연구에서는 기존의 문헌에에서 알려진 대로 우리 나라 아동이 다른 나라와 비교하여 높은 수면 문제 점수를 보였다. 또한 수면습관의 문제가 행동, 정서, 주의력 및 학습 문제와 유의한 상관이 있었다.

학습을 강조하는 최근의 우리나라의 사회문화적 분위기와 늦은 시간까지 인터넷과 핸드폰 같은 매체를 사용하는 경향 등을 고려하면 우리나라 아동의 수면이 침해받을 위험이 높 다.10) 아동의 수면 문제는 학습, 인지, 정서, 주의력 모두에 유의 한 문제를 동반할 수 있으므로 임상에서도 아동기 수면이 생활 전반에 미치는 영향을 고려하여 아동의 수면양상을 평가하는 것이 전반적인 아동의 수행에 미치는 인자를 파악하는데 도움 이 될 수 있을 것으로 보인다. 향후 충분한 수의 아동을 대상 으로 전향적인 연구를 시행하여 수면습관과 아동 발달의 여러 영역에 미치는 영향을 입증하는 것이 필요할 것이다.

중심 단어: 초등학생 · 수면 · 행동 · 정서 · 주의력 · 학습.

\section{References}

1) Sheldon SH. Introduction to pediatric sleep medicine. Philadelphia: Elsevier Saunders;2005.

2) Gozal D. Sleep-disordered breathing and school performance in children. Pediatrics 1998;102:616-620.

3) Pilcher JJ, Huffcutt AI. Effects of sleep deprivation on performance: a meta-analysis. Sleep 1996;19:318-326. 
4) Owens JA, Fernando S, Mc Guinn M. Sleep disturbance and injury risk in young children. Behav Sleep Med 2005;3:18-31.

5) Fallone G, Acebo C, Seifer R, Carskadon MA. Experimental restriction of sleep opportunity in children: effects on teacher ratings. Sleep 2005;28:1561-1567.

6) Carskadon MA, Acebo C, Jenni OG. Regulation of adolescent sleep: implications for behavior. Ann N Y Acad Sci 2004;1021:276291.

7) Sadeh A, Gruber R, Raviv A. Sleep, neurobehavioral functioning, and behavior problems in school-age children. Child Dev 2002;73: 405-417.

8) Yang CK, Kim JK, Patel SR, Lee JH. Age-related changes in sleep/ wake patterns among Korean teenagers. Pediatrics 2005;115:250256.

9) Mindell JA, Sadeh A, Wiegand B, How TH, Goh DY. Cross-cultural differences in infant and toddler sleep. Sleep Med 2010;11:274-280.

10) Hong HJ, Kim YS, Jon DI, Soek JH, Hong N, Harkavy-Friedman JM, et al. Mental health and extracurricular education in Korean first graders: a school-based cross-sectional study. J Clin Psychiatry 2011;72:861-868.

11) Seo WS, Sung HM, Lee JH, Koo BH, Kim MJ, Kim SY, et al. Sleep patterns and their age-related changes in elementary-school children. Sleep Med 2010;11:569-575.

12) Owens JA, Spirito A, McGuinn M. The Children's Sleep Habits Questionnaire (CSHQ): psychometric properties of a survey instrument for school-aged children. Sleep 2000;23:1043-1051.

13) Choi J, Yoon IY, Kim HW, Chung S, Yoo HJ. Differences between objective and subjective sleep measures in children with attention deficit hyperactivity disorder. J Clin Sleep Med 2010;6:589-595.

14) Kim HW, Yoon IY, Cho SC, Kim BN, Chung S, Lee H, et al. The effect of OROS methylphenidate on the sleep of children with attention-deficit/hyperactivity disorder. Int Clin Psychopharmacol 2010;25:107-115.

15) Oh KJ, Lee HL. Empirically derived syndromes of Korean children and adolescents : analyses of child behavior checklist data from clinic refered boys aged 4-5, 6-11, and 12-16. Korean J Clin Psychol 1990;9:33-55.

16) Jeon SY, Shin MS, Cho SC, Kim BN. Diagnostic validity of the K$\mathrm{ABC}$ and The K-LDES for children with learning disorder and learning problem. J Korean Acad Child Adolesc Psychiatry 2003; 14:209-217.
17) So YK, Noh JS, Kim YS, Ko SG, Koh YJ. The reliability and validity of Korean parent and teacher ADHD rating scale. J Korean Neuropsychiatr Assoc 2002;41:283-289.

18) Kim JW, Park KH, Choi MJ. Screening for attention deficit/hyperactivity disorder in community mental health services for children. J Korean Neuropsychiatr Assoc 2004;43:200-208.

19) Cho SC, Kim JW, Shin MS, Hwang JW, Han SW, Park KH, et al. Behavioral and emotional problems in children with nocturnal enuresis: results of a multicenter study. J Korean Neuropsychiatr Assoc 2005;44:730-735.

20) Sadeh A, Mindell J, Rivera L. "My child has a sleep problem" : a crosscultural comparison of parental definitions. Sleep Med 2011;12:478482.

21) Seo HE, Kwon S, Lee HW, Kim JS. Clinical analysis of sleep disorders in Korean children. J Korean Child Neurol Soc 2010;18:74-82.

22) Son KG, Park JH, Shon SM, Kim JS, Lee JH, Cho YW. The prevalences of anxiety and depressive disorders in patients of pediatric sleep disorders. J Korean Child Neurol Soc 2009;17:200-208.

23) An H, Ahn JH, Bhang SY. The association of psychosocial and familial factors with adolescent suicidal ideation: A populationbased study. Psychiatry Res 2010;177:318-322.

24) Chae KY. Physiology of sleep. 1. Korean J Pediatr 2007;50:711-717.

25) Yoon JM, Lee HR, Lee KH. Characteristics of Sleep Disorders in Childhood and Adolescence. J Korean Child Neurol Soc 2007;15: 185-191.

26) Kim JK, Lee JH, Lee SH, Hong SC, Cho JH. School performance and behavior of Korean elementary school students with sleep-disordered breathing. Ann Otol Rhinol Laryngol 2011;120:268-272.

27) Corkum P, Tannock R, Moldofsky H, Hogg-Johnson S, Humphries T. Actigraphy and parental ratings of sleep in children with attention-deficit/hyperactivity disorder (ADHD). Sleep 2001;24:303-312.

28) Epstein R, Chillag N, Lavie P. Starting times of school: effects on daytime functioning of fifth-grade children in Israel. Sleep 1998;21: 250-256.

29) Owens J, Maxim R, McGuinn M, Nobile C, Msall M, Alario A. Television-viewing habits and sleep disturbance in school children. Pediatrics 1999;104:e27.

30) Hobson JA, Pace-Schott EF. The cognitive neuroscience of sleep: neuronal systems, consciousness and learning. Nat Rev Neurosci 2002;3:679-693. 